\title{
V9 - ESTUDO DE ESTABILIDADE DE MEIOS DE CULTURA UTILIZADOS NO PROCESSO PRODUTIVO DA VACINA Haemophilus Influenzae b (CONJUGADA)
}

$\underline{\text { Aline Rodrigues Venancio das Neves }}{ }^{1}$, Núbia Boechat $^{2}$, Maria de Lourdes Leal ${ }^{1}$.

1. Bio-Manguinhos, Fundação Oswaldo Cruz, Rio de Janeiro, Brasil.

2. Farmanguinhos, Fundação Oswaldo Cruz, Rio de Janeiro, Brasil.

Objetivos: Este trabalho descreve o estudo de estabilidade realizado com os meios de cultura que fazem parte da etapa de fermentação do processo produtivo da vacina Haemophilus influenzae b conjugada (Hib) viabilizando a determinação do holding time dos mesmos. Com o objetivo de atender as recomendações da ANVISA, deve ser avaliado o holding time dos produtos intermediários, uma vez que os resultados de estabilidade disponibilizados pela empresa responsável pela transferência de tecnologia precisam ser estabelecidos localmente.

Métodos: O holding time fornecido pela GlaxoSmithKline-Bélgica durante a transferência de tecnologia foi utilizado como base para definição dos tempos do estudo de estabilidade dos cinco meios: meio sólido empregado na semeadura da bactéria, meio líquido utilizado no pré-cultivo e cultivo final em biorreator, meio sólido para controle de pureza do cultivo e a solução de extrato de levedura dialisado, que faz parte da composição de todos os meios. Devido à falta de legislação específica para a realização de estudos de estabilidade de meios de cultura, foram preconizados os testes de $\mathrm{pH}$, esterilidade e promoção de crescimento. A premissa utilizada no desenho do estudo se baseou no preparo de três lotes distintos e análise em seis tempos diferentes $(0,15,30$, 45, 60 e 90 dias) e para o meio sólido de semeadura da bactéria utilizam-se outros intervalos de tempo $(0,10,15,20,30$ e 45 dias $)$.

A avaliação de $\mathrm{pH}$ e esterilidade foi realizada em todos os meios. Entretanto, o teste de promoção de crescimento foi definido para os meios líquidos de pré-cultivo e cultivo final em biorreator e para os meios sólidos (semeadura da bactéria e controle de pureza), com inoculação da cepa referência de Hib ATCC 10211/INCQS 00398. O meio líquido para cultivo de Hib utilizado no fermentador passará por testes em escala industrial chegando até a etapa de purificação do polissacarídeo de Hib. 
Resultados: O estudo do dialisado de extrato de levedura foi finalizado com aprovação nos testes de $\mathrm{pH}$ e esterilidade em todos os tempos. Com base nestes resultados, foi possível alterar a validade deste insumo de trinta para noventa dias. A avaliação da estabilidade dos outros meios está em andamento e os resultados parciais têm sido promissores.

Conclusão: Estes resultados preliminares demonstram grandes possibilidades de extensão da validade de todos os meios de cultura envolvidos no estudo e com isso uma considerável redução de custos, perdas de processo. Além de possibilitar o atendimento a eventuais demandas (estoque estratégico) e flexibilizar as atividades de rotina na produção da vacina conjugada. 